\title{
Analisis Strategi Pemasaran Objek Wisata Kebun Binatang Kasang Kulim Kecamatan Siak Hulu Kabupaten Kampar
}

\author{
Ona Gustina Mardianti ${ }^{1}$; Syahdanur ${ }^{1}$; Susie Suryani ${ }^{1 *}$
}

\section{INFO A RTIKEL}

\section{Penulis:}

${ }^{1}$ Fakultas Ekonomi, Universitas Islam Riau, Pekanbaru, Indonesia

*E-mail: susie@eco.uir.ac.id

\section{Untuk mengutip artikel ini:}

Mardianti OG, Syahdanur \& Suryani S 2018, 'Analisis strategi pemasaran objek wisata kebun binatang kasang kulim kecamatan siak hulu kabupaten kampar', Jurnal Ekonomi KIAT, vol. 30, no. 1, hal. 37-43.

\section{Akses online:}

www.jurnalkiatuir.com

E-mail:

kiat@journal.uir.ac.id

Di bawah lisensi:

Creative Commons AttributeShareAlike $4.0 \quad$ International Licence

\section{ABSTRAK}

This study aims to determine the marketing strategy of the tourist attraction of the Kasang Kulim Zoo, the Siak Hulu sub-district, Kampar District. The population of this study was visitors who came to the Kasang Kulim Zoo, Siak Hulu Sub-District, Kampar District and from the company, with a number of respondents as many as 100. In this study sampling using non probability sampling and respondent sampling was done by accidental sampling technique. This research is qualitative research and uses interviews, questionnaires, and documentation as a method of data collection. Data were analyzed using SWOT analysis with identification of internal and external variables. Internal variables indicate that location is the main strength in the kasang kulim zoo in kampar district with 0.012 with values and 4 based on rating. From the external variables, the results from EFAS show that the Kasang Kulim zoo has good opportunities. As a result of the opportunity, the Kasang Kulim zoo is in quadrant 1 , which is a position where the company is considered to be in a favorable situation because of its opportunities and strength. In this case, the Company can take advantage of opportunities by maximizing strength.

Katakunci: Marketing Strategy, SWOT Analysis, Zoo

\section{Pendahuluan}

Indonesia sebagai negara yang terkenal memiliki banyak potensi wisata alam maupun budaya juga menjadikan pariwisata sebagai salah satu industri yang berperan dalam devisa negara. Banyak objek wisata di indonesia telah di kenal tidak hanya di dalam negeri tetapi juga di mancanegara. Oleh karena itu pengembangan kepariwisataan di Indonesia dilakukan di seluruh daerah, untuk itu di bentuk Dinas Pariwisata yang berfungsi sebagai lembaga yang berwenang dalam penertiban peraturan, memberikan intruksi dan bantuan teknik untuk memungkinkan kalangan investor maupun masyarakat berusaha meningkatkan pariwisata di daerahnya. Perkembangan suatu objek wisata dihasilkan dari sistem Pemasaran yang baik, terukur dan jelas. Pemasaran sangat penting dilakukan pada suatu objek wisata karena merupakan suatu perubahan keadaan kondisi yang diterapkan.Tanpa dilakukan Pemasaran pada suatu objek wisata maka tidak ada perkembangan dan perubahan yang terjadi terhadap objek tersebut.

Dengan pemasaran sektor kepariwisataan yang baik, sektor pariwisata mampu menciptakan lapangan kerja, lapangan usaha bagi masyarakat serta dapat menggerakkan perekonomian bagi Negara maupun daerah. Riau adalah sebuah provinsi yang terletak di
Pulau Sumatera dan beribu kotakan Pekanbaru. Luas wilayah provinsi Riau adalah $87.023,66 \mathrm{~km}^{2}$ dan terdiri dari 3.214 pulau besar dan pulau kecil. Riau merupakan salah satu provinsi yang sangat potensial bagi perkembangan kemajuan pariwisata mengingat provinsi ini memiliki kebudayaan yang kental, keagamaan yang kuat dan merupakan jalur lalu lintas antar daerah.

Kurang suksesnya pemasaran kepariwasataan di kabupaten Kampar selama ini tidak terlepas dari kurang tepatnya strategi pemasaran yang dilakukan oleh pihak pengelola wisata, pemerintah dan masyarakat. Kendala-kendala yang mengakibatkan objek pariwisata kurang berkembang dikarenakan sumber daya manusia bidang pariwisata di kabupaten Kampar masih lemah dan minimnya infrastruktur menjadi kendala utama dalam mengembangkan sektor pariwisata di daerah ini. Sampai saat ini masih banyak kawasan yang memiliki potensi wisata dikabupaten Kampar belum bisa ditempuh karena keterbatasan infrastruktur yang kurang bagus mengakibatkan sebagian masyarakat tidak mau berkunjung di kebun binatang kasang kulim tersebut. Untuk melihat objek wisata apa saja yang dimiliki oleh kabupaten Kampar dapat dilihat pada Tabel 1 berikut. 
Tabel 1. Objek wisata kabupaten Kampar

\begin{tabular}{|l|l|l|l|}
\hline \multicolumn{1}{|c|}{ Wisata Eko dan Alam } & \multicolumn{1}{c|}{ Wilayah Wisata } & \multicolumn{1}{c|}{ Wisata Religi/Budaya } & \multicolumn{1}{c|}{ Wilayah Wisata } \\
\hline Air Terjun Sungai Osang & Kec. XIII Koto Kampar & Stanum Masjid Islamic Center & Kec. Bangkinang \\
\hline Air Terjun Binamang & Kec. XIII Koto Kampar & Mesjid Jamik & Kec. Bangkinang \\
\hline Waduk PLTA Koto Panjang & Kec. XIII Koto Kampar & Desa Wisata Pulau Belimbing & Kec. Bangkinang Barat \\
\hline Aguari & Kec. XIII Koto Kampar & Desa Buluh Cina & Kec. Siak hulu \\
\hline Bendungan Ompang Oewai & Kec. Bangkinang Seberang & Tugu Equator Lipat & Kec. Kampar Kiri \\
\hline Bendungan Sungai Paku & Kec. Kampar Kiri & Makam Datuk Alif Dan Wahid & Kec. Kampar \\
\hline Bendungan Simbat Kampar & Kec. Kampar Timur & Makam Syech Addul Ghani & Kec. XIII Koto Kampar \\
\hline Bendungan Sungai Tibun & Kec. Kampar Timur & Makam Syech Burhanuddin & Kec. Kampar Kiri \\
\hline Bukit Cadika & Kec. Bangkinang & Candi Muara Takus & Kec. XIII Koto \\
\hline Kebun Binatang Kasang Kulim & Kec. Siak Hulu & Kerajaan Gunung Sahilan & Kec. Gunung Sahilan \\
\hline Bukit Na'ang & Kec. Bangkinang & Rumah Adat Lontiok & Kec. Salo \\
\hline Air Terjun Bertingkat & Kec. Kampar Kiri Hulu & Museum Kendil Kemilau Emas & Kec. Bangkinang Barat \\
\hline
\end{tabular}

Sumber: Dinas Pariwisata dan Olahraga Kampar (2017)

Dari data diatas dapat diketahui bahwa kabupaten Kampar memiliki banyak potensi objek wisata yang terdiri dari wisata ekosistem/alam maupun wisata religi/budaya. Namun potensi-potensi yang dimiliki sektor wisata tersebut belum dikembangkan secara optimal sehingga perindustrian objek wisata kabupaten Kampar masih memiliki peranan kecil terhadap Pendapatan Asli Daerah.

Salah satu objek wisata tersebut adalah Kebun Binatang Kasang Kulim yang berada di Kecamatan Siak Hulu Kabupaten Kampar. Pada kondisi sekarang perkembangan objek wisata Kebun Binatang ini belum dapat dikatakan baik. Hal ini dapat dilihat dari keberadaan Kebun Binatang itu sendiri yang masih belum dapat dikatakan layak untuk menjadi objek wisata serta masih banyaknya masyarakat yang tidak mengetahui keberadaan tempat objek wisata tersebut. Hal ini terlihat dari tingkat jumlah pengunjung dan tingkat kepuasaan masayarakat yang masih rendah.

Padahal Kebun Binatang Kasang Kulim sendiri mempunyai potensi yang besar dalam memajukan pariwisata daerah mengingat objek wisata ini merupakan satu-satunya taman marga satwa yang ada di provinsi Riau. pelayanan infrastruktur dan kawasan yang mempunyai kelayakan dalam pengembangan wisata kabupaten Kampar. Objek Wisata Kebun Binatang Kasang Kulim kabupaten kampar pekanbaru merupakan salah satu Objek Wisata satu-satunya yang ada di Pekanbaru, dari harga tiket masuk kebun binatang yang berbedabeda sekitar Rp 20.000 untuk dewasa dan anak-anak Rp 15.000 per orang nya.

Tabel 2. Jumlah pengunjung kebun binatang kasang kulim (2014-2017)

\begin{tabular}{cc}
\hline Tahun & Jumlah Pengunjung \\
\hline 2014 & 118.805 \\
2015 & 100.060 \\
2016 & 120.402 \\
2017 & 113.047 \\
\hline
\end{tabular}

Sumber: Kebun Binatang Kasang Kulim (2017)
Berdasarkan Tabel 2 dapat dilihat bahwa jumlah pengunjung di kebun binatang kasang kulim dari tahun ke tahunnya mengalami penurunan. Hal ini dikarenakan sistem Pemasaran di Kebun Binatang Kasang Kulim belum dapat dikatakan baik sehingga tingkat pengetahuan masyarakat terhadap pemasaran pada objek wisata ini masih rendah dan pengunjung tidak merasa nyaman dengan kondisi kandang hewan yang kurang bersih serta penyediaan fasilitas yang kurang memadai.

Rendahnya jumlah pengunjung wisatawan di objek-objek wisata di kabupaten kampar disebabkan oleh masih lemahnya sistem pemasaran. Oleh karena itu perlu dikembangkan suatu model pemasaran objek dan daya tarik wisata serta fasilitas wisata sebagai upaya untuk menungkatkan jumlah kunjungan wisatawan di kebupaten Kampar. Morrison (2002) menjelaskan pemasaran merupakan proses yang berlangsung seara terus menerus dan berkelanjutan, dimana kegiatan yang terjadi di dalamnya adalah merencanakan, meneliti, mengimplementasikan, mengawasi dan melakukan penilaian dalam berbagai aktivitas yang diranang untuk memuaskan baik kebutuhan dan keinginan pelanggan dan tujuan organisasinya. Agar kegiatan tersebut berlangsung seara efektif, maka pemasaran memerlukan usaha setiap orang dalam sebuah organisasi dan dapat dibuat kurang atau lebih efektif oleh tindakan-tindakan dari kelengkapan organisasi.

\section{Telaah Pustaka}

\subsection{Definisi strategi pemasaran}

Menurut Assauri (2011: 168), strategi pemasaran pada dasarnya adalah rencana yang menyeluruh, terpadu, dan menyatu di bidang pemasaran, yang memberikan panduan tentang kegiatan yang akan dijalankan untuk dapat tercapainya tujuan pemasaran suatu perusahaan.

Menurut Kotler (2004: 81) strategi pemasaran adalah sebuah pola piker pemasaran yang akan dipakai untuk memcapai tujuan pemasaran suatu perusahaan, bisa berisi strategi spesifik untuk pasar 
sasaran, penetapan posisi, bauran pemasaran, dan besarnya pengeluaran pemasaran.

Tjiptono (2002: 6) Strategi pemasaran adalah alat fundemental yang direncanakan untuk mencapai perusahaan dengan mengembangkan keunggulan bersaing yang berkesinambungan melalui pasar yang dimasuki dan program pemasaran yang digunakan untuk melayani pasar sasaran tersebut.

Strategi pemasaran pada dasarnya rencana yang menyeluruh, terpadu dan menyatu di bidang pemasaran yang memberikan panduan tentang kegiatan yang akan dijalankan untuk mencapai tujuan pemasaran suatu perusahaan. Begitu pentingnya sebuah strategi pemasaran bagi kegiatan sebuah perusahaan, khususnya dalam mendasari kegiatan pemasaran.Tanpa didasari strategi yang tepat maka sebuah kegiatan pemasaran tidak akan berjalan dengan maksimal.

\subsection{Faktor yang mempengaruhi strategi pemasaran} Menurut Fandy (2000: 7) ada beberapa faktor-faktor strategi pemasaran suatu perusahaan untuk menanggapi setiap perubahan kondisi pasar. Faktor-faktor strategi pemasaran tersebut adalah sebagai berikut:

1) Lingkungan. Analisis terhadap faktor lingkungan seperti pertumbuhan populasi dan peraturan pemerintah sangat penting untuk mengetahui pengaruh yang ditimbulkannya pada bisnis perusahaan.

2) Pasar. perusahaan perlu selalu memperhatikan dan mempertimbangkan faktor-faktor seperti ukuran pasar, tingkat pertumbuhan, tahap perkembangan,trend dalam sistem distribusi,pola perilaku pembeli, permintaan musiman,segmen pasar yang ada saat ini atau yang dapat dikembangkan lagi dan peluang-peluang yang belum terpenuhi.

3) Persaingan. Dalam kaitannya dengan persaingan, setiap perusahaan perlu memahami siapa pesaingnya, bagaimana posisi produk atau pasar pesaing tersebut, apa strategi mereka, kekuatan dan kelemahan pesaing, struktur biaya pesaing.

4) Kemampuan internal. Setiap perusahaan perlu menilai kekuatan dan kelemahan dibandingkan para pesaingnya. Penilaian tersebut didasari pada faktor-faktor seperti teknologi, sumber daya finansial,kemampuan manufaktur, kekuatan pemasarandan basis pelanggan yang dimiliki.

5) Perilaku konsumen. Perilaku konsumen perlu dipantau dan dianalisis karena hal ini sangat bermanfaat bagi pengembangan produk, desain produk, penetapan harga, pemilihan saluran distribusi dan penentuan strategi promosi.

6) Faktor analisis ekonomi. Dalam analisis ekonomi, perusahaan dapat memperkirakan pengaruh setiap peluang pemasaran terhadap kemungkinan mendapatkan laba.

\section{Metode Penelitian}

\subsection{Lokasi penelitian dan responden}

Penelitian ini dilaksanakan di Kebun Binatang Kasang Kulim Kecamatan Siak Hulu Kabupaten Kampar. Populasi dalam kajian ini adalah Pengunjung yang datang ke kebun binatang Kasang Kulim Kecamatan Siak Hulu Kabupaten kampar dan dari pihak perusahaan. Sampel yang dipilih dengan menggunakan teknik aksidental sampling. Sehingga populasi adalah Pengunjung yang datang ke kebun binatang Kasang Kulim Kecamatan Siak Hulu Kabupaten kampar dan dari pihak perusahaan. Jumlah pengunjung yang diambil sebanyak 100 responden

\section{Hasil Penelitian dan Pembahasan}

\subsection{Gambaran umum responden}

4.1.1.Responden berdasarkan jenis kelamin

Responden dalam penelitian ini terdiri dari pengunjung yang dating ke kebun binatang kasang kulim kecamatan siak hulu kabupaten Kampar. Responden yang memberi tanggapan terhadap itemitem pernyataan yang disebarkan melalui kuesioner sebanyak 100 orang meliputi $53 \%$ adalah perempuan 53 orang, dan laki-laki sebanyak $47 \%$ atau 47 orang.

\subsubsection{Tingkat usia}

Selanjutnya tingkat usia pengunjung yang datang ke kebun binatang kasang kulim tingkat usia 15-20 sebanyak 28 orang, 21-22 tahun sebanyak 37 orang, 26-30 tahun sebanyak 14 orang, 31- 40 sebanyak 12 orang, 41 ke atas sebanyak 9 orang.

\subsection{Analisis IFAS dan EFAS}

Tabel 3. Analisis IFAS strategi pemasaran kebun binatang kasang kulim

\begin{tabular}{|c|c|c|c|}
\hline Faktor-faktor Strategi Internal & \multirow{2}{*}{ Bobot } & \multirow{2}{*}{ Rating } & \multirow{2}{*}{$\begin{array}{c}\text { Bobot } x \\
\text { Rating }\end{array}$} \\
\hline Kekuatan (Strength) & & & \\
\hline 1. Daya tarik wisata kebun binatang kasang kulim & 0,010 & 4 & 0,04 \\
\hline 2. Pelayanan yang ramah & 0,010 & 3 & 0,03 \\
\hline 3. Kualitas produk & 0,011 & 4 & 0,044 \\
\hline 4. Lokasi yang strategis & 0,012 & 3 & 0,036 \\
\hline Total S & $\mathbf{0 , 0 4 3}$ & & $(+) 0,15$ \\
\hline \multicolumn{4}{|l|}{ Kelemahan (Weakness) } \\
\hline 1. Kurangnya variasi hewan yang ada di kebun binatang kasang kulim & 0,010 & 4 & 0,04 \\
\hline 2. Kurangnya Sarana prasarana & 0,08 & 4 & 0,32 \\
\hline 3. Tidak adanya paket wisata & 0,010 & 3 & 0,03 \\
\hline 4. Permodalan & 0,010 & 4 & 0,04 \\
\hline
\end{tabular}




\begin{tabular}{|c|c|c|c|}
\hline 5. Kualitas SDM & 0.009 & 3 & 0,027 \\
6. Kurangnya kerjasama dengan pemerintah maupun pihak ketiga & 0,010 & 4 & 0,04 \\
\hline Total W & $\mathbf{0 , 0 5 7}$ & & $\mathbf{( - )} \mathbf{0 , 4 9 7}$ \\
\cline { 1 - 2 } \cline { 1 - 2 } & Total & $\mathbf{1 , 0 0}$ & $\mathbf{( + )} \mathbf{0 , 3 4 7}$ \\
\hline
\end{tabular}

Sumber: Data olahan (2018)

Tabel 4. Analisis EFAS strategi pemasaran kebun binatang kasang kulim

\begin{tabular}{|c|c|c|c|}
\hline Faktor-Faktor Strategi Eksternal & \multirow{2}{*}{ Bobot } & \multirow{2}{*}{ Rating } & \multirow{2}{*}{$\begin{array}{c}\text { Bobot } x \\
\text { Rating }\end{array}$} \\
\hline Peluang (Opportunities) & & & \\
\hline 1. Pengembangan kebun binatang kasang kulim & 0,010 & 4 & 0,04 \\
\hline 2. Kepuasan konsumen & 0,009 & 3 & 0,027 \\
\hline 3. Pertumbuhan pasar & 0,011 & 3 & 0,033 \\
\hline 4. Daya beli konsumen & 0,010 & 4 & 0,04 \\
\hline 5. Kondisi ekonomi & 0,010 & 3 & 0,03 \\
\hline 6. Keuntungan & 0,009 & 4 & 0,036 \\
\hline 7. Loyalitas pelanggan & 0,009 & 4 & 0,036 \\
\hline Total O & $\mathbf{0 , 0 6 8}$ & & $(+) 0,242$ \\
\hline \multicolumn{4}{|l|}{ Ancaman (Threats) } \\
\hline 1. Banyaknya objek wisata baru yang di buka di daerah kabupaten kampar & 0,011 & 3 & 0,033 \\
\hline 2. Perkembangan teknologi dan promosi & 0,009 & 3 & 0,027 \\
\hline 3. Produk yang tidak bervariasi & 0,012 & 3 & 0,036 \\
\hline Total T & $\mathbf{0 , 0 3 2}$ & & $(-) 0,096$ \\
\hline Total & $\mathbf{1 , 0 0}$ & & $(+) 0,146$ \\
\hline
\end{tabular}

Sumber: Data olahan (2018)

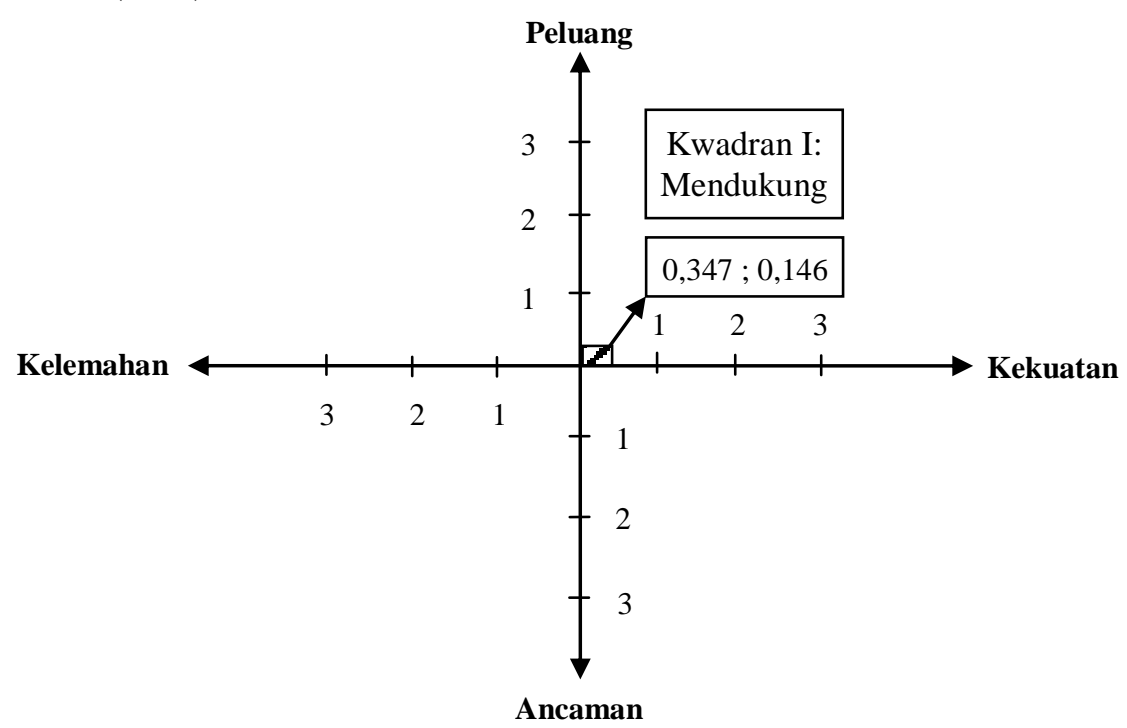

Gambar 1. Analisis SWOT

Dari gambar diatas, menunjukkan bahwa kebun binatang kasang kulim berada pada posisi kwadran 1, yaitu dimana perusahaan berada dalam situasi yang menguntungkan karena memiliki peluang dan kekuatan, sehingga dapat memanfaatkan peluang yang ada dengan menutupi kelemahan yang dimiliki. Strategi yang harus diterapkan dalam kondisi ini adalah peluang untuk menutupi kelemahan, sedangkan kekuatan digunakan untuk menghadapi ancaman.

\begin{tabular}{|c|l|l|}
\hline \multicolumn{1}{|c|}{ Kekuatan (S) } & \multicolumn{1}{|c|}{ Kelemahan $(\mathbf{W})$} \\
\cline { 2 - 3 } & $\begin{array}{l}\text { 1. Daya tarik wisata kebun binatang } \\
\text { kasang kulim } \\
\text { 2. Pelayanan yang ramah }\end{array}$ & $\begin{array}{l}\text { 1. Kurangnya variasi hewan yang } \\
\text { ada di kebun binatang } \\
\text { 2. Kurangnya sarana prasarana } \\
\text { 3. Tidak adanya paket wisata } \\
\text { 4. Keterbatasan modal } \\
\text { 5. Kualitas produk } \\
\text { 6. Kondisi ekonomi }\end{array}$ \\
\hline
\end{tabular}




\begin{tabular}{|c|c|c|}
\hline $\begin{array}{c}\text { Peluang }(\mathrm{O}) \\
\end{array}$ & \begin{tabular}{|r} 
Strategi SO \\
\end{tabular} & \begin{tabular}{|c} 
Strategi WO \\
\end{tabular} \\
\hline $\begin{array}{l}\text { 1. Daya beli konsumen semakin } \\
\text { pesat dilihat dari penjualan tiket } \\
\text { masuk kebun binatang } \\
\text { 2. Kebun binatang satu-satunya } \\
\text { yang ada di pekanbaru,riau }\end{array}$ & \begin{tabular}{|l} 
1. Kualitas SDM semakin diting- \\
katkan, agar konsumen merasa \\
semakin puas \\
2. Sarana dan prasarana terhadap \\
konsumen semakin ditingkatkan, \\
sehingga konsumen akan merasa \\
nyaman ketika berwisata, dan \\
demi menjaga loyalitas konsumen
\end{tabular} & $\begin{array}{l}\text { 1. Memperbaiki kualitas SDM, } \\
\text { misalnya memberikan training } \\
\text { bagi para pekerja lapangan. } \\
\text { 2. Menambah spesies hewan-hewan } \\
\text { langka agar pengujung tertarik } \\
\text { berwisata di kebun binatang } \\
\text { kasang kulim. }\end{array}$ \\
\hline & & \\
\hline 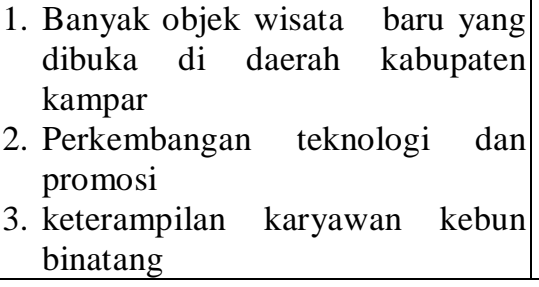 & $\begin{array}{l}\text { 1. Dengan lokasi yang lebih dapat } \\
\text { mengantisipasi banyaknya objek } \\
\text { wisata baru yang dibuka di daerah } \\
\text { kabupaten kampar } \\
\text { 2. Kualitas produk semakin diting- } \\
\text { katkan. }\end{array}$ & $\begin{array}{l}\text { 1. Dengan permodalan yang baik, } \\
\text { dimungkinkan bagi perusahaan } \\
\text { untuk memperbaiki teknologi dan } \\
\text { promosi yang digunakan, sehing- } \\
\text { ga dapat membantu perkemba- } \\
\text { ngan kebun binatang. }\end{array}$ \\
\hline
\end{tabular}

Gambar 2. Matriks SWOT

\subsection{Pembahasan}

Berdasarkan hasil penelitian ini juga sejauh dengan penelitian yang dilakukan oleh (2014), di mana strategi pemasaran produk, pelayanan, konsumen, penyediaan fasilitas, variasi wisata dan lokasi perusahaan. Hal yang sama juga dijelaskan dalam penelitian Widiasti dan Andriani (2012) di mana menjelaskan strategi pemasaran yang ditetapkan oleh kepariwisata buleleng di antaranya strategi kekuatan (strenghts) dan peluang (opportunity) di antaranya mengkemas paket wisata dalam berbagai harga dan variasi dalam menciptakan program yang berbasis budaya ramah lingkungan. Penelitian ini menggunakan metode analisis SWOT yang mana kebun binatang kasang kulim memiliki masing-masing skor yang berbeda yaitu:

1) Kekuatan (strenghts). Kekuatan adalah suatu keunggulan sumber daya,keterampilan atau kemampuan lainnya yang relatif terhadap pesaing dan kebutuhan dari pasar yang dilayani atau hendak dilayani oleh perusahaan. Dari rekapitulasi responden kebun binatang kasang kulim maka dapat dilihat rekapitulasi kekuatan responden yang di berikan pengunjung yang datang ke kebun binatang kasang kulim, maka dapat diketahui bahwa tingkat kategori mengenai kekuatan pada kebun binatang kasang kulim kecamatan siak hulu kabupaten kampar berada pada kategori baik, karena total bobot nilai sebesar 1565 .

2) Kelemahan (weaknesses). Kelemahan adalah suatu keterbatasan/kekurangan dalam sumber daya, keterampilan dan kemampuan yang secara serius menghalangi kinerja suatu perusahaan. Dari rekapitulasi responden kebun binatang kasang kulim maka dapat dilihat rekapitulasi kelemahan responden yang diberikan pengunjung yang datang ke kebun binatang kasang kulim, maka dapat diketahui bahwa tingkat kategori mengenai kelemahan pada kebun binatang kasang kulim kecamatan siak hulu kabupaten kampar berada pada kategori baik, karena total bobot nilai sebesar 2481.

3) Peluang (opportunities). Peluang adalah situasi utama yang menguntungkan dalam lingkungan perusahaan dan bergerak untuk memperoleh laba. Dari rekapitulasi responden kebun binatang kasang kulim maka dapat dilihat rekapitulasi peluang responden yang di berikan pengunjung yang datang ke kebun binatang kasang kulim, maka dapat diketahui bahwa tingkat kategori mengenai peluang pada kebun binatang kasang kulim kecamatan siak hulu kabupaten kampar berada pada kategori baik, karena total bobot nilai sebesar 2744.

4) Ancaman (threats). Ancaman adalah situasi utama yang tidak menguntungkan dalam lingkungan perusahaan. Dari rekapitulasi responden kebun binatang kasang kulim maka dapat dilihat rekapitulasi kekuatan responden yang di berikan pengunjung yang datang ke kebun binatang kasang kulim, maka dapat diketahui bahwa tingkat kategori mengenai ancaman pada kebun binatang kasang kulim kecamatan siak hulu kabupaten kampar berada pada kategori baik, karena total bobot nilai sebesar 1221. Maka dapat dijelaskan bahwa secara keseluruhan strategi pemasaran pada objek wisata kebun binatang kasang kulim kecamatan siak hulu kabupaten kampar meliputi kekuatan, kelemahan, peluang, ancaman sudah baik, dilihat dari jumlah skor keseluruhan yaitu 8118.

Dari hasil membobotkan IFAS dan EFAS strategi pemasaran kebun binatang kasang kulim maka dapat memposisikan kebun binatang berada pada posisi kwdran 1, yaitu di mana perusahaan berada dalam situasi yang menguntungkan karena memiliki peluang dan kekuatan, sehingga dapat memanfaatkan peluang yang ada dengan menutupi kelemahan yang dimiliki, dan matrik SWOT kebun 
binatang kasang kulim dari kekuatan dan kelemahan kualitas SDM semakin ditingkatkan, agar konsumen merasa semakin puas, sarana dan prasarana terhadap konsumen semakin ditingkatkan sehingga konsumen akan merasa nyaman ketika berwisata, menambah spesies hewan-hewan langka agar pengunjung tertarik berwisata dikebun binatang kasang kulim.

\section{Simpulan}

Berdasarkan hasil analisis data pada penelitian ini maka dapat dirumuskan kesimpulan berikut ini:

1) Strategi pemasaran yang dilakukan kebun binatang kasang kulim menerapkan marketing mix yaitu: Produk, promosi, pelayanan, dan lokasi. Produk: di sini dimaksud adalah hewan-hewan yang ada di kebun binatang kasang kulim yang di pelihara dan di jaga kebersihannya, agar pengunjung yang datang tertarik dengan produk yang ditawarkan pihak kebun binatang tersebut. Promosi: pihak kebun binatang kasang kulim kecamatan siak hulu mempromosikan kebun binatang melalui media sosial seperti: Instagram, whatapp, Facebook, dan aplikasi lainnya. Pelayanan: pelayanan yang di berikan pihak kebun binatang ramah dan sopan sehingga pengunjung yang datang merasa nyaman dan damai saat menikmati wisata dikebun binatang. Lokasi: Kebun Binatang Kasang Kulim adalah kebun binatang satu-satunya yang berada di Pekanbaru, Riau, dan menjadi pusat kunjungan para wisatawan lokal karena lokasi kebun binatang yang strategis memudahkan pengunjung datang ke kebun binatang dengan aman.

2) Strategi Pemasaran Kebun binatang kasang kulim berada pada posisi Kwadran 1 yaitu mendukung strategi yang agresif. Artinya perusahaan berada dalam situasi yang menguntungkan karena memiliki peluang dan kekuatan, sehingga dapat memanfaatkan peluang yang ada dengan memaksimalkan kekuatan yang telah dimiliki.

3) Objek wisata kebun binatang kasang kulim dapat dikatakan mempunyai peluang bisnis yang besar. Dimana perusahaan memiliki cukup baik, kekuatan dan juga peluang. Kekuatan perusahaan ditunjukkan oleh indikator Lokasi yang strategis, Daya tarik wisata kebun binatang kasang kulim, Pelayanan yang ramah, Kualitas produk. Sedangkan yang menjadi kelemahan bagi perusahaan adalah tentang Kualitas SDM, Kurangnya sarana prasarana, Permodalan, kurangnya variasi hewan yang ada di kebun binatang kasang kulim. Dan untuk peluang perusahaan ditunjukan pada indikator Pertumbuhan pasar, daya beli konsumen, kondisi ekonomi, berkembangnya iklim pariwisata

\section{Referensi}

\section{Al-Qurán}

Alma, Buchari. (2007). Manajemen Pemasaran Jasa dan Pemasaran Jasa. Bandung: Alfabeta

Badan Pusat Statistik (BPS) Provinsi Riau. 2017. Pekanbaru. http//:www.bpsriau.go.id yang ada di provinsi Riau. Sementara untuk ancaman perusahaan adalah banyaknya objek wisata baru yang dibuka didaerah kabupaten kampar, perkembangan teknologi dan promosi.

4) Dari Penerapan marketing mix di dalam kebun binatang kasang kulim dapat penulis menganalisis yaitu: Produk adalah segala sesuatu yang dapat dipergunakan untuk memenuhi kebutuhan pengunjung dari segi hewan-hewan yang ada di kebun binarang tersebut, Promosi dan pelayanan sangat penting di dalam kebun binatang kasang kulim sebagai menarik pengunjung yang datang ke kebun binatang kasang kulim dan lokasi.

\section{Saran}

Melihat kondisi yang ada, diharapkan perusahaan tetap dapat mempertahankan kekuatan bisnis yang ada dan jika mampu terus ditingkatkan untuk memperoleh kesempatan pemasaran (peluang bisnis) yang lebih besar. Selain itu perusahaan juga harus berusaha untuk mengatasi beberapa kelemahan yang ada.Sehingga diharapkan kelemahan-kelemahan tersebut nantinya dapat diubah menjadi kekuatan bagi perusahaan. Dan berkaitan dengan hal tersebut saran penulis adalah:

1) Kualitas SDM. Pemberian training semaksimal mungkin kepada para tenaga lapangan, sehingga diharapkan dapat menunjang kinerja karyawan dalam melayani konsumen/pengunjung.

2) Perubahan Teknologi. Jika memungkinkan, disediakan sistem booking tiket masuk secara online bagi para calon konsumen/pengunjung. Sehingga dapat lebih memudahkan calon konsumen/pengunjung karena lebih menghemat waktu dan tenaga, terlebih untuk calon konsumen /pengunjung dari luar kota. Lalu untuk penjualan merchandise, makanan serta minuman dapat menggunakan barcode system, dengan begitu kasir tidak perlu repot menginput kode tiket, sehingga dapat lebih menghemat waktu. Kemudian jika memungkinkan disediakan fasilitas tambahan berupa mesin ATM, sehingga dapat memudahkan pengunjung jika ingin mengambil uang untuk keperluan berwisata.

3) Perusahaan harus melakukan strategi pemasaran dengan baik yang sesuai dengan kondisi yang ada, sehingga proses pemasaran dapat berjalan dengan lancar. Dan perusahaan juga harus mempertahankan strategi tersebut agar memperoleh pasar yang lebih luas tak hanya pasar domestik saja tapi juga di mancanegara, sehingga dapat sejajar dengan pariwisata yang lain.

Basu Swastha. 2002. Manajemen Pemasaran. Edisi Kedua. Jakarta: Penerbit Liberty.

Buchari Alma. 2007, Manajemen Pemasaran \& Pemasaran Jasa. Bandung: CV. Alfabeta 
Basu, Swastha. 2002. Manajemen Pemasaran. Edisi Kedua. Cetakan Kedelapan. Libery, Jakarta

Buchari, Alma, 2007. Manajemen Pemasaran dan Pemasaran Jasa. Alfabeta, Bandung.

Gerry. C, Susana. C. \& Nogueira. F. 2008. Tracking Student Entrepreneurial Potential: Personal Attributes and the Propensity for Business Start Ups after Graduation in a Portuguese University. International Research Journal Problems and Perspectives in Management, 6(4): 45-53.

Gitosudarmo, Indriyo. 2008. Manajemen Pemasaran. Edisi kedua, Cetakan keenam. Penerbit: BPFEYogyakarta

Gurbuz, G. \& Aykol, S. 2008, Entrepreneurial Intentions of Young Educated Public in Turkey. Journal of Global Strategic Management, 4(1): 47-56.

I Made Suradnya, 2011. Destinasi Pariwisata Berkelanjutan. Jurnal Iimiah Manajemen \& Akuntansi STIE Triatma. Vol 16, No. 2 Edisi Desember 2011 Strategi Pemasaran

Johnston, K.A, Andersen, B.K., Davidge-Pitts, J. \&Ostensen-Saunders, M. 2010. Identifying ICT Entrepreneurship Potential in Students. Paper was presented at the Proceedings of Informing Science \& IT Education Conference (InSITE), Italy, 21-24 Juni.

Kotler, P \& Amstrong, G. (2001). Dasar-dasar Pemasaran Edisi IX. Jakarta: PT Indek

Kotler, Philip \& Kevin Lane Keller. 2012. Marketing Manajemen, 14e, Global Edition, Pearson Education Limited, England.

Kotler, P. (2000), Manajemen Pemasaran, Jakarta: Erlangga

Kotler, P. (2002), Manajemen Pemasaran, Edisi Milenium 1, Jakarta: Prenhallindo

Kertajaya, Hermawan. (2002). Marketiing Plus 2000; Siasat Memenangkan Persaingan Global. Jakarta: Gramedia Pustaka Utama

Lupiyoadi, R. Dan Hamdani, A. (2006), Manajemen Pemasaran Jasa, Edisi 2, Jakarta: Salemba Empat

Mazzarol, T., T. Volery, N. Doss, dan V. Thein, 1999. "Factors influencing small business startups". International Journal of Entrepreneurial Behaviour and Research 5 (2).

Nachrowi D Nachrowi, dan Hardius Usman 2006. Pendekatan Populer dan Praktis Ekonometrika (Untuk Analisis Ekonomi dan Keuangan). LPFEUI. Jakarta
Oka A.Yoety, 2008 Pemasaran Pariwisata, PT Pradnya Paramitha: Jakarta

Priyanto S.H. 2008. Di dalam Jiwa ada Jiwa: The Backbone and the Social Construction of Entrepreneurships. Pidato Pengukuhan Guru Besar Universitas Kristen Satya Wacana.

Rangkuti, Freddy. 2004. Analisis SWOT Teknik Membedah Kasus Bisnis. Gramedia Pusat Utama, Jakarta

Rangkuti, F. (2006), Analisis SWOT Teknik Membedah Kasus Bisnis, Jakarta: Gremedia: Pustaka Umum

Sondang, S.P (1995), Manajemen Strategik,Edisi 1, Jakarta: Sinar Grafika

Suryana, (2006). Kewirausahaan Pedoman Praktis: Kiat dan Proses Menuju Sukses, disi Ketiga, Penerbit Salemba, Jakarta

Stewart,W.H.,Watson, W.E., Carland, J.C. \& Carland, J.W. 1998. A Proclivity for Entrepreneurship: A Comparison of Entrepreneurs, Small Business Owners, and Corporate Managers". Journal of Business Venturing, 14(2): 189-214.

Tjiptono, Fandy, Strategi Pemasaran, Edisi Kedua, Andi, Yogyakarta, 1997

Tjiptono, F. (1998), Strategi Pemasaran, Edisi 2, Yogyakarta: Andy Offset

Tjiptono, F. (2011), Pemasaran Jasa, Yogyakarta: Bayumedia Publishing.

Tjiptono, Fandy. (2000). Strategi Pemasaran. Yogyakarta: Andi

Tjahjono, H.K. \& Ardi, H. 2008. Kajian Niat Mahasiswa Manajemen Universitas Muham madiyah Yogyakarta untuk Menjadi Wirausaha Utilitas Jurnal Manajemen dan Bisnis, 16(1): 4663.

Vesper, K.H. \& McMullan, W.E. 1988. Entrepre neurship: Today Courses, Tomorrow degrees? Entrepreneurship Theory and Practice, 13(1): 7 13

Zeithaml, Valarie A \& Bitner, Mary Jo (2000). Service Marketing. Singapore: Mc Graw-Hill Companies Inc.: 3-287.

Zimmerer, W.T. 2002. Essentials of Entrepreneurship and Small Business Management. Third Edition. New York: Prentice-Hall.

http://www.konsistensi.com/2013/04/pengumpulandata-penelitian-dengan.html 